\title{
ANAESTHESIA FOR LIGATION OF PATENT DUCTUS ARTERIOSUS IN CHILDREN
}

\author{
A. W. ConN, M.D., B.SC.(MED), F.R.C.P.(C), and' C. I. JUNKIN, M.B. ${ }^{1}$
}

A PATENT DUCTUS ARTERIOSUS is the second most conamon lesion in congenital heart disease (1). Its incidence in the general population has been estimated to be between $1: 2,500$ and $1: 5,000$ by one author (2), and $1: 3,850$ by others (3). Surgical ligation of a persistent ductus was first carried out by Gross in 1939 (4). At present, it is probably the most frequently performed cardiovascular operation. Anaesthesia for this procedure is simple in the usual case but the presence of complicating factors adds considerably to the risk of the operation. Those patients requiring ligation during infancy and those with increased pulmonary vascular resistance present the most serious problems. This paper deals with 104 consecutive paediatric cases which were diagnosed as patent ductus arteriosus and came to operation.

\section{Pathological Physiology}

The ductus arteriosus is an arterial channel connecting the left pulmonary artery to the ventral-lateral surface of the aorta, close to the origin of the left subclavian artery. The ductus may vary considerably in length, width, shape, and thickness. In foetal life, blood flows from pulmonary artery to aorta, but at birth it reverses direction. The flow through the ductus may increase the pulmonary circulation to two to four times that of the systemic system and cause pulmonary hypertension.

With large shunts, the increased pulmonary venous return produces left atrial and left ventricular hypertrophy. The left ventricle may fail, and this can occur even in infancy; it may then result in right ventricular failure. The ductus may undergo aneurysmal changes or become the site of bacterial endocarditis. In addition, because so much blood is passing through the pulmonary system, the general development of the child may be seriously retarded.

A serious complication is increased pulmonary vascular resistance with severe pulmonary hypertension. This leads to a reversal of flow and subsequent development of right heart failure. If ligation of the ductus is performed at this stage, death may occur promptly owing to closure of the "escape" route of the pulmonary circuit. The cause of this condition is not known, but the degree of pulmonary hypertension, the volume flow through the ductus, the extent of pulmonary vasoconstriction, and individual variation are all factors.

\section{Prognosis}

The average age of death was 35 to 38 years in a group of 60 patients with persistent ductus who survived to adolescence and were untreated. It was estimated that when untreated patients reached the age of 17 years, they have only half the normal life expectancy (5).

${ }^{1}$ From the Department of Anaesthesia, Hospital for Sick Children, and the University of Toronto, Toronto. 
Surgical treatment of the uncomplicated case carries a very low mortality; 0 in 108 cases (6), 0 in 116 cases (7), 0 in 300 cases (8), 3 in 138 cases (9), and 10 in 482 cases (10). If persistent ductus is associated with pulmonary hypertension, there is an 18 per cent operative mortality and, if a marked right to left shunt exists, the operative mortality is 56 per cent (11). In a world survey of surgical treatment of 2,929 children under 14 years with patent ductus, the mortality was 2.3 per cent (12).

If cardiac failure occurs in infancy, operation should be performed promptly $(3,15)$. In uncomplicated cases, operation may be postponed to 3 or 4 years of age $(3,13)$. After the age of 5 years the incidence of complications rises sharply (14).

The presence of pulmonary hypertension with increased vascular resistance is the principal contraindication to operation (16)

\section{ANAESTHESIA}

In this series, there was a total of 104 children, ranging in age from 3 weeks to 15 years. They are grouped according to age in Table $\mathbb{I}$. The preoperative complications consisted of cardiac failure, pulmonary hypertension, failure to thrive, or repeated respiratory infections. All children were labelled patent ductus and were anaesthetized for ligation of the lesion. Various agents and techniques were employed, but the following anaesthetic management was preferred.

TABLE I

\begin{tabular}{lrrr}
\hline & No. of cases & Complications & Deaths \\
\hline Males & & & \\
Birth-12 mos. & 5 & 5 & 2 \\
$12-24$ mos. & 5 & 2 & 0 \\
$2-8$ yrs. & 16 & 7 & 0 \\
$9-15$ yrs. & 33 & & \\
Total & & & \\
Females & 14 & 11 & 3 \\
Birth-12 mos. & 6 & 3 & 0 \\
12-24 mos. & 41 & 4 & 0 \\
$2-8$ yrs. & 10 & 1 & 0 \\
$9-15$ yrs. & 71 & & \\
Total & & & \\
\hline
\end{tabular}

\section{Preoperative Visit}

The anaesthetist must thoroughly examine the patient preoperatively Complicating illness not due to the cardiovascular lesion results in cancellation of operation. The cardiovascular system is examined in detail. The typical patient has a precordial heave and thrill with a continuous "machinery" murrinur in the pulmonary area. The $\mathbb{E C G}$ shows left ventricular hypertrophy and there may be minimal cardiomegally as shown by chest X-ray. The atypical patient with increased pulmonary resistance may have such symptoms and signs as dyspnoea, chest pain or cyanosis, a systolic murmur only, and a markedly increased 
pulmonary second sound. The ECG shows combined or right ventricular hypertrophy, and chest X-ray may show an increased heart shadow.

Premedication consists of meperidine (0.75 mg./lb.) and atropine (.012 $\mathrm{mg}$./lb.). Morphine is used in older patients in a dosage of $1 \mathrm{mg} . / 10 \mathrm{lb}$. body weight. Sedation is minimal, as apprehension is rarely a prominent feature and drug depression must be avoided. In the infant with failure, atropine is given immediately preceding anaesthesia to avoid increasing the heart rate and the degree of failure.

\section{Induction}

In the older child a "sleep" dose of $2 / 2$ per cent thiopentone is administered slowly followed by succinylcholine ( $1 \mathrm{mg}$. $/ 3 \mathrm{lb}$.). With the onset of complete relaxation and following adequate ventilation, the larynx is sprayed with 2 per cent lignocaine. The patient is intubated and artificially ventilated with nitrous oxide-oxygen mixture $(60: 40)$ until spontaneous respirations return, when halothane is added. An 18-gauge needle with stylet is inserted in the right saphenous vein as a "spare" entrance to a vein. A cut-down is started after induction to avoid undue disturbance of the child.

In the infant, intramuscular succinylcholine $(2 \mathrm{mg}$. $\mathrm{lb}$.) is used while nitrous oxide-oxygen-halothane is administered. The intramuscular dose may have to be repeated until the cut-down is functioning.

\section{Maintenance}

Nitrous oxide-oxygen-halothane mixtures is the anaesthetic of choice, supplemented by intermittent succinylcholine. Hyperventilation is begun as the chest is opened and is maintained throughout the operative period. Blood loss is carefully calculated and accurate replacement is made.

\section{Monitoring}

The heart sounds are monitored using an oesophageal stethoscope. On closure of the ductus, the diastolic component of the murmur should always disappear. The systolic component frequently persists but is usually without significance.

The blood pressure is monitored using a Collins oscillometer. Following ligation, the diastolic blood pressure rises in the typical patient. In those patients with small flows through the ductus there may be no detectable rise in diastolic pressure. The effect of ligation on systolic blood pressure is variable.

The $\mathbb{E C G}, \mathbb{E E G}$, and rectal temperature are monitored routinely.

In selected patients, monitoring of the pulmonary arterial (PA) pressure may be carried out. Those patients with typical patent ductus show no change in PA pressure when their ductus is temporarily occluded (see Fig. 1). If the PA pressure falls in patients with pulmonary hypertension, then the degree of increased resistance is minimal and the ductus may be ligated in safety. If the PA pressure is unaltered or rises in patients with severe pulmonary hypertension (see Fig. 2), then the degree of increased resistance is marked and ligation of the ductus carries a high mortality. 


\section{$27 / 11 / 59$ D. C. P D A LIGÅTED}

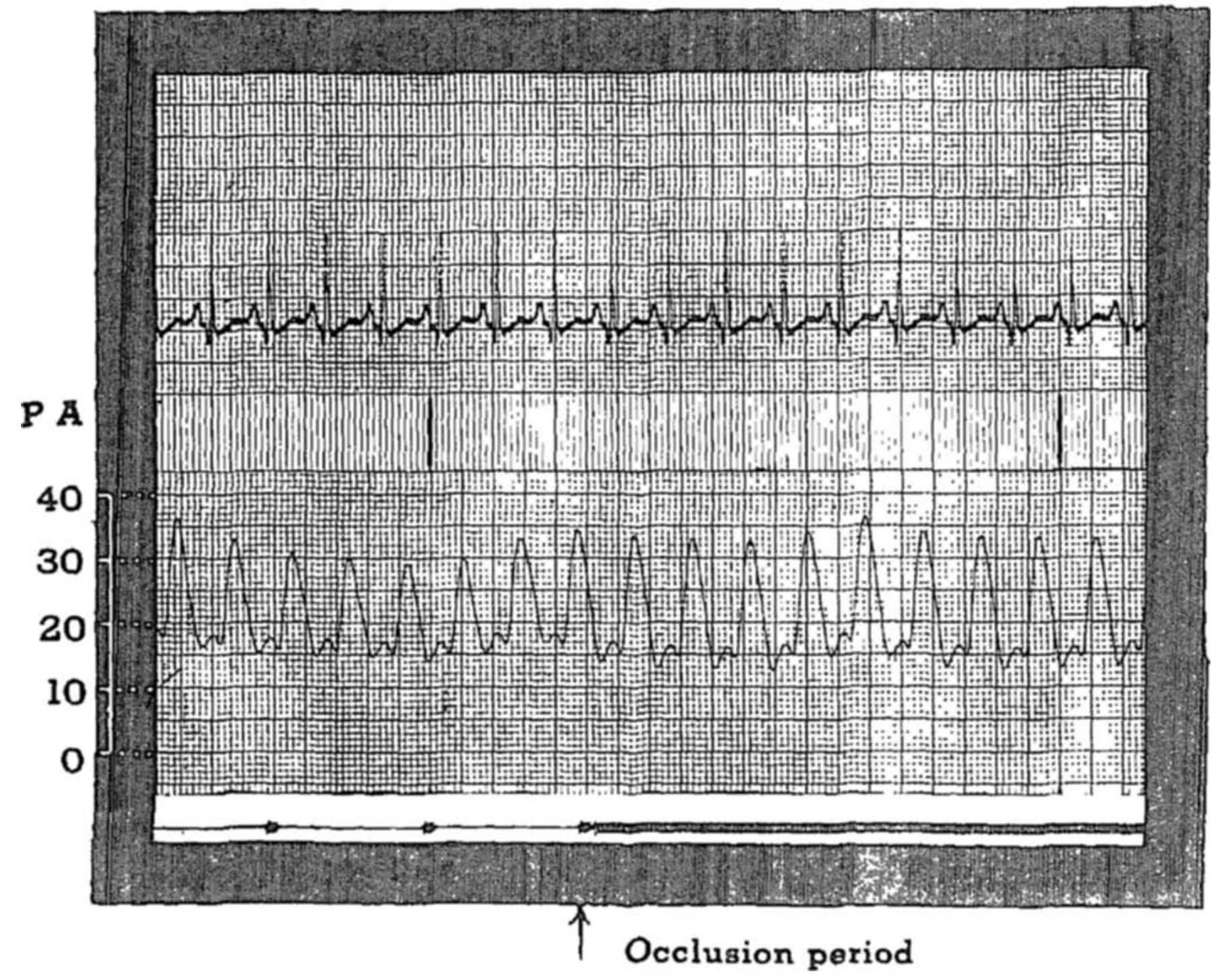

Figune I

Recovery

The operative time averages $1 \frac{1}{2}$ hours and the patient is awake before leaving the operating room. He is taken to the recovery room and remains there for a minimum of 4 hours for close observation. Meperidine ( $1 \mathrm{mg} / 10 \mathrm{lb}$.) intravenously is used for sedation and repeated as necessary. No oxygen tent is used and blood replacement is rarely necessary,

\section{Complications}

After hospital discharge follow-up records were not completed on every patient. However, the known complications are listed. There were 5 deaths in this series with the following post-mortem findings: :

(1) Age 3 weeks: Ligated PDA, patent foramen ,ovile (PFO), total anomalous pulmonary venous drainage, repaired diaphragmatic hernia, bilateral bifid ureters and pneumothorax

(2) Age 3 months: Ligated PDA, preductal co-arctation, ventricular septal defect, $\mathrm{PFO}$, congestive heart failure and pulmonary atelectasis

(3) Age 3 months: Ligated PDA, A-P window, PFO, bronchopneumonia 


\section{4/4/59 K. C. P D A NOT LIGATED}

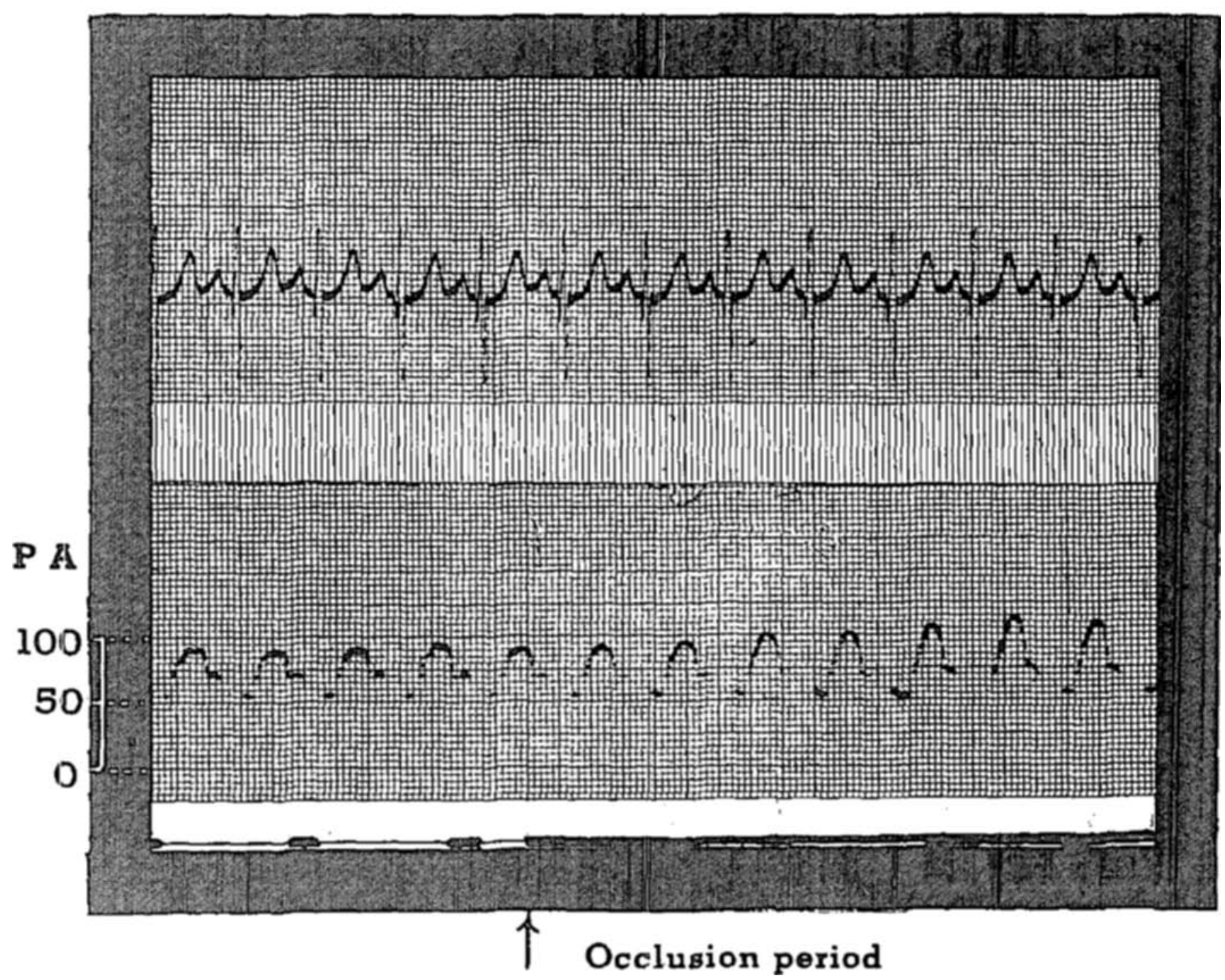

FrgURe 2

(4) Age 6 months: Ligated PDA, repaired ventricular septal defect (pulmonary artery opened for A-P window but ventricular defect found instead and repaired through pulmonary valve)

(5) Age 7 months: Ligated PDA, ventricular septal defect, PFO, and gross cardiomegaly

In the remainder of the series, the lesser complications are given below:

(1) Pulmonary (pleural effusion 1, surgical emphysema 1, small tear in Iung 1 , excessive secretions 1 ; brobchial stenosis requiring tracheotomy 1)

(2) Neurogenic (phrenic paralysis 1, transient recurrent laryngeal nerve paralysis 1, transient brachial plexis injury 1)

(3) Cardiovascular (no ligation because of (a) increased vascular resistance 1, (b) A-P window instead of PDA, incomplete closure 1)

\section{DISCUSSION}

The preceding data are similar to those found by other cardiovascular units. They emphasize features of great importance in patients with persistent ductus arteriosus. These are $(a)$ age at operation and $(b)$ the presence of complicating factors. 
It is known that some infants with patent ductus arteriosus develop severe cardiac failure during the first year of life. Between 20 and 25 per cent of children with isolated patent ductus die in infancy, but all could be saved with prompt medical and surgical treatment (15). It is also evident that many children with patent ductus have additional cardiovascular lesions as well as other abnormalities. The operative risks are considerable but with specialized care, many of these could be saved.

The presence of increased pulmonary resistance carries a grave prognosis. Pulmonary hypertension alone increases the risk of operation (11). The operative mortality is prohibitive in those patients with severe hypertension and high resistance $(11,17)$. In patients with reversed or largely reversed shunts who have a hopeless prognosis otherwise, it is justifiable to do a thoracotomy for a trial occlusion of the ductus with observation of the pulmonary artery pressure changes.

It is probable that with increased duration of high pulmonary pressure and arteriolar resistance, irreversible changes may eventually occur which maintain the pulmonary hypertension, in spite of surgery (18). Therefore, the facts all argue for surgical treatment at an early age in patients with patent ductus arteriosus.

\section{SUMMTARY}

This paper deals with a total of 104 cases which came to operation diagnosed as patent ductus arteriosus. The pathological disturbances, the anaesthetic management, and complications are discussed.

\section{RÉSUMí}

Ce travail contient l'étude de 104 cas de cardiopathie dirigés vers la chirurgie avec le diagnostié provisoire de persistence du canal artériel. Les troubles physiopathologiques, la conduite de l'anesthésie et les complications sont discutés.

\section{ACKNOWLEDGMENTS}

Thanks are extended to Dr. IV. T. Mustard and Dr. G. A. Trusler for permission to review these cases.

\section{REFERENCES}

1. KeITH, J. D., Rowe, R. D., \& VLAD, P. Heart Disease in Infancy and Chilthood, p. 3. New York: Macmillan Company (1958).

2. Anderson, R. C. Causative Factors Underlying Congenital Heart Malformations. Pediatrics 14: 143 (Aug., 1954).

3. Keith, J. D., Rowe, R. D., \& Vlad, P. Heart Disease in Infancy and Childhood, pp. 133-161, New York: Macmillan Company (1958).

4. Gross, R. E., \& Hubbafd, J. P. Surgical Ligation of a Patent Ductus Arteriosus, J.A.M.A. 112: 729 (1939). 
5. Keys, A., \& Shapiro, M. J. Patency of the Ductus Arteriosus in Adults, Am. Heart J. 25: $158(1943)$.

6. HAY, J. D., \& WArd, O. C. Patent Ductus Arteriosus. Arch. Dis. Childhood 31: 279 (1956).

7. Ash, R., \& Fisher, D. Manifestations and Results of Treatment of Patent Ductus Arteriosus in Infancy \& Childhood. Pediatrics 16: 695. (1955).

8. MicQuiston, W. O. Anaesthesia for Cardiac Surgery in Children. Pediatric Clinics North America (Feb., 1954).

9. Nicks, R., \& Molloy, P. J. Surgery of Persistent Ductus Arteriosus. Brit. Med. J. 2: 578 (Sept. 8, 1956).

(10) Gross, R. E. The Patent Ductus Arteriosus. Am. J. Medicine 12: 472 (1952).

(11) Ellis, F. H. Jr., Kirklin, J. W., Callahan, J. A. \& Wood, E. H. Patent Ductus Arteriosus with Pulmonary Hypertension. J. Thoracic Surg. 31: 268, (1956).

12. Waternan, D. H., \& Samipson, P. C., \& Bailey, C. P. The Surgery of Patent Ductus. Dis. of Chest. 29: 102 (1956).

13. Mustard, W. T. Personal communication.

14. Clatsworthy, H. W., \& McDonald, V. G. Optimum Age for Surgical Closure of Patent Ductus Arteriosus. J.A.M.A. 167: 444 (May 24, 1958).

15. Ziegler, R. F. The Importance of Patent Ductus Arteriosus in Infants. Am. Heart J. 43: $553(1952)$.

16. Editorial. Patent Ductus Arteriosus. Lancet 2: 1252 (Dec. 15, 1956).

17. Anderson, R. C., Adams, P., \& VARCo, L. R. Patent Ductus Arteriosus with Reversall of Flow. Pediatrics 18: 410 (1956).

18. Anderson, I. M., \& Coles, M. M. T. Patent Ductus Arteriosus with Pulmonary Hypertension. Thorax 10:338 (1955). 